\title{
GUIA ESPIRITUAL
}

René Descartes

REGLA PRIMERA. Dirigir el espiritu de modo que forme juicios sólidos y verdaderos de todos los obietos que se presentan: tal debe ser el fin del estudio.

REGLA II. Debemos ocuparnos solamente de aquellos objetos que pueden ser conocidos por nuestro espíritu de un modo cierto e indubitable.

REGLA III. En el objeto que el estudio se propone se debe buscar no las opiniones de los demás a las propias conjeturas, sino lo que se puede ver claramente, con evidencia, o deducir con certeza: porque la ciencia se adquiere de ese y no de otro modo.

REGLA IV. El método es necesario para la investigación de la verdad.

REGLA V. Estriba el método en el orden y disposición de las cosas a las que debemos dirigir el espiritu para descubrir alguna verdad. Lo seguiremos fielmente si reducimos las proposiciones obscuras y confusas a las más sencillas, y si, partiendo de la intuición de las cosas más faciles, tratamos de elevarnos poco a poco al conocimiento de todas las demás.

REGLA VI. A objeto de distinguir las cosas más sencillas de las obscuras, y seguir con orden esta investigación, es necesario ver, en cada serie de objetos y verdades deducidas directamente de otras verdades, cuál es la cosa más sencilla y la mayor, igual o menor distancia a que está de todas las otras.

REGLA VII. Para completar la ciencia, es necesario por un movimiento continuo del pensamiento, recorrer todos los objetos que se relacionan con el fin que nos proponemos, abrazándolos en una enumeración metódica y suficiente.

REGLA VIII. Si en la serie de las cosas que examinamos, hallamos alguna que no podemos comprender bien, nos abstendremos de examinar las siguientes porque el trabajo que empleáramos sería superfluo.

REGLA IX. Es preciso dirigir todas las fuerzas del espíritu a las cosas más fáciles y menos importantes, y detenemos en ellas mucho tiempo hasta acostumbramos a ver la verdad clara y distintamente.

REGLA X. Para que el espíritu logre sagacidad es necesario ejercitarlo, encontrando cosas que hayan sido ya descubiertas y recorriendo las artes, aun las menos importantes, y sobre todo las que explican o suponen el orden. 
REGLA XI. Si después de considerar intuitivamente algunas proposiciones simples, concluímos otra, es muy util recorrerlas todas con un movimiento continuo del pensamiento, reflexionar sobre sus relaciones mutuas y concebir claramente y al mismo tiempo el mayor numero posible de ellas; porque haciendo esto nuestra ciencia adquiere mucha más certeza y nuestro espíntu mucha mayor extensión.

REGLA XII. Es necesario emplear todos los recursos de la inteligencia, de la imaginación, los sentidos y la memoria, lo mismo para tener una intuición de las proposiciones simples, que para comparar en forma conveniente lo que se busca con lo que se conoce, a fin de descubrirle por este medio, o para encontrar las cosas que necesitan ser comparadas entre si; en una palabra, no hay que olvidar ninguno de los medios que el hombre puede emplear.

REGLA XIII. Cuando comprendemos perfectamente una cuestión, es preciso abstraerla de toda concepción superflua, reducirla a sus más simples elementos y subdividirla en tantas partes como sea posible, por medio de la enumeración.

REGLA XIV. La misma regla ha de aplicarse a la extensión real de los cuerpos; y es necesario representarla a la imaginación por medio de figuras claras; de esta manera será mucho mejor comprendida por la inteligencia.

REGLA XV. Es de gran utilidad trazar estas formas y presentarlas a los sentidos externos para conservar la atención en el espíritu.

REGLA XVI. Acerca de las dimensiones que no exigen la atención inmediata del espíritu, aunque sean necessarias para la conclusión, es más útil designarlas con figuras cortas que con figuras enteras; de este modo no se equivocará la memoria y el pensamiento no se verá obligado a dividirse para retener aquellas dimensiones, mientras se aplica a la investigación de las otras.

REGLA XVII. Debese examinar directamente la dificultad propuesta, haciendo abstracción de que sean conocidos unos términos $y$ desconocidos otros, y siguiendo por la verdadera ruta su mutua dependencia.

REGLA XVIII. Para esto no hay necesidad sino de cuatro operaciones: adición, sustracción, multiplicación y división; con frecuencia las dos últimas no deben hacerse aqui, por no complicar inutilmente las cuestiones y porque más adelante podrán ser verificadas con más facilidad.

(Editorial TOR - Rio de Janeiro/Buenos Aires) 